uma rede aberta, a autora compara o processo de favelização - de ocupações informais - com o mato que nasce discretamente nas bordas e que logo acaba ocupando a totalidade dos vazios deixados pela máquina imobiliária. Estabelece, assim, um confronto entre a lógica do mato (da "erva daninha") e a lógica da árvore, ou seja, entre o sistema erva/rizoma do pensamento da multiplicidade e aquele configurado no pensamento binário ainda dominante. Insiste na oposição entre uma cultura acentrada, não-hierárquica, instável, e uma cultura arborescente, hierárquica e enraizada. Explica, assim, como um rizoma, a exemplo do mato, da erva, está sempre no meio, não têm começo nem fim, transborda, e evoca a idéia de infiltração, de um escoamento que preenche vazios. O processo de favelização, na surpreendente comparação ao mato, escapa à idéia de projeto, cresce onde não se espera, formando encraves no território urbano.

$\mathrm{Na}$ parte final do trabalho, apropriando-se da proposição criativa "jardins em movimento" do paisagista Gilles Clément e contestando ao mesmo tempo sua idéia de "arte involuntária" e sua aplicação às favelas, refere-se à suposta intenção da prefeitura do Rio de Janeiro de "preservar" as favelas. Contrariando o senso comum e o consenso generalizado dos responsáveis pelas intervenções do programa oficial "FavelaBairro", a autora propõe: em lugar de preservar as favelas o que "seria necessário preservar é o seu próprio movimento", ou melhor, "territórios em movimento", ainda melhor, "bairros em movimento", procedendo através de quase não-intervenções, ou seja, intervenções mínimas.

Depois dessas breves considerações sobre o trabalho à guisa de resenha, ocorre perguntar que lição o leitor de Estética da ginga poderá tirar? Sem dúvida, a atitude de ousar, de contrapor-se à forma de pensar consensual, lançando no intercâmbio de idéias, imagens conceituais novas que podem receber um desejável acolhimento em relação aos fundamentos da arquitetura e do urbanismo. Como ato criativo, o trabalho constitui um singular acontecimento, pois, como tal, pressupõe ainda um processo de atualização, isto é, como sistema aberto, propício a conexões e heterogeneidades sob a égide da lógica da multiplicidade, instrumental teórico extremamente rico em noções e conceitos. Sem dúvida, no âmbito dos estudos teóricos produzidos no País e que se relacionam com os funda- mentos da arquitetura e urbanismo, a Estética da ginga pode ser considerado um ponto de inflexão.

Para concluir, valeria acrescentar que, no caso específico do processo de ocupação de terrenos e criação de favelas, questão chave do trabalho, os processos urbanos, especificamente as produções de arquitetura e urbanismo, podem vir a ser considerados tanto "máquinas abstratas" de sobrecodificação efetuadas pelo "aparelho de Estado" quanto "máquinas de guerra" que procuram escapar à sobrecodificação e resistir aos "aparelhos de captura” que se encontram a serviço do aparelho de Estado. Essa situação extremamente conflitante em nosso país acaba por exigir, compulsoriamente, ao lado das realizações de natureza estética, no espaço físico da percepção urbana, um inadiável posicionamento ético, passando inevitavelmente pelo viés político, que poderá promover uma melhor qualidade de vida, hoje tão aviltada e insegura sob a hegemonia do paradigma científico/tecnológico.

\section{MODERNIDADE E MORADIA. HABITAÇÃO COLETIVA NO RIO DE JANEIRO NOS SÉCULOS XIX E XX}

Lílian Fessler Vaz

Rio de Janeiro: 7 Letras, 2002.

Eloisa Petti Pinheiro

Partindo das primeiras habitações coletivas no Rio de Janeiro - os cortiços e as estalagens do século XIX - até chegar ao edifício de apartamentos contemporâneo, e aos arranha-céus dos anos 30 do século $\mathrm{XX}$, a autora analisa não apenas as diversas manifestaçôes de habitação coletiva como também as mudanças tipológicas e populacionais ao longo do período abordado. Lílian demonstra de que forma as habitaçóes coletivas surgem como habitação popular, transformando-se, ao final do período estudado, em habitação das classes média e alta, compreendendo os diferentes espaços construídos como produtos dos sistemas econômico, político e cultural.

Considerando a habitação coletiva como manifestação própria da modernidade, a autora percorre os distintos tipos de moradia propondo-se a fazer uma leitura da modernidade, ultrapassando os limites da ar- 
quitetura e do urbanismo. O livro aborda ainda, em relação ao caráter simbólico, a habitação coletiva do século XIX, símbolo da pobreza, da doença, da promiscuidade e da insalubridade, substituída, no século XX, pela moradia multifamiliar, moderna e funcional, expressão privilegiada da modernidade.

A metodologia adotada, uma pesquisa através de classificados dos imóveis, permite rastrear as transformações ocorridas e verificar na habitação, como a condição do que é coletivo passará a definir a inserção da cidade na modernidade. Também são analisadas as transformaçôes urbanas, arquitetônicas e simbólicas através de um levantamento de plantas de estalagens, avenidas, vilas operárias, casas de cômodos e de apartamentos, prédios para renda e hotéis, e fica claro como o edifício de apartamentos inclui uma série de características presentes nos seus antecedentes e rejeita outras.

Lílian define, assim, que o surgimento dos apartamentos não ocorre como uma evolução dos tipos de casas ou quartos enfileirados - as estalagens, avenidas e vilas -, mas representa uma profunda ruptura nessa evolução, apesar de ser um padrão que aprofunda a tendência de agrupar, cada vez mais, pessoas em uma área menor, tornando mais coletiva ou mais socializada a moradia. O novo modelo a ser reproduzido, segundo a autora, é o prático-simbólico, no caso do Rio de Janeiro, onde a habitação não é apenas um abrigo, construção ou elemento isolado, mas também um componente dos sistemas espaciais em que se insere e que define seu complexo valor de uso.

Tendo como limites espacial e temporal a cidade do Rio de Janeiro de 1850 a 1937, o livro se desenvolve em três partes e cinco capítulos, começando pela história da habitação coletiva em que são destacados não só os "grandes momentos de ruptura, mas também as permanências, fortes impactos e sutis modificaçōes, além de uma série de contradições inerentes ao processo de transformação da moradia nos tempos modernos" (p.16).

Adotando o conceito de habitação coletiva como várias unidades habitacionais abrigadas sob o mesmo teto e construídas sobre o mesmo lote onde se compartilham certos equipamentos, a autora identifica diferenças em cada momento histórico. Das habitaçōes coletivas insalubres, cortiços e estalagens, passa-se às casas higiênicas - como um modelo ideológico ao qual são incorporadas inovaçōes técnicas e sanitárias de alto custo. Além disso, há também as avenidas, classificadas, por Lílian, como "tipo em transição", e consideradas estalagens higienizadas que abrigam novos moradores - uma vez que os antigos não podem pagar os aluguéis -, excluindo, assim, os benefícios da modernização dos seus destinatários específicos. Segundo a autora, "iniciava-se o processo de melhoramento das moradias mediante a substituição dos seus moradores" (p.45).

$\mathrm{Na}$ análise do processo de especialização funcional e social do espaço urbano, o uso do solo e as classes sociais, categorias que antes se misturavam, agora passam a ocupar áreas exclusivas. A população pobre instala-se em locais onde os casebres são tolerados, em terrenos de difícil edificação e de propriedade indefini$\mathrm{da}$, enquanto a classe média, que tem um aumento progressivo a partir dos anos 20 do século XX, partem para novas opçōes de moradia: casas isoladas ou em série nos bairros servidos por modernos bondes elétricos e/ou "auto-ônibus", e com infra-estrutura de serviços e comércio. As avenidas cedem lugar às vilas, definidas como "conjunto de habitaçōes isoladas em edifícios separados ou não, e dispostos de modo a formarem ruas e praças interiores sem caráter de logradouro público" (Decreto 2.087 de 19/01/1925).

As vilas, uma vez desvinculadas das habitações coletivas, vêm atender à emergente classe média e passam por modificaçôes, buscando privacidade, utilizando novos materiais e novas técnicas que permitem um melhor aproveitamento dos lotes: começam as construçôes em altura, mesmo antes que se difundisse o uso do concreto armado.

Por fim, surgem os apartamentos nos anos 20, um novo padrão de habitação no Rio de Janeiro que terá sua melhor expressão em Copacabana onde a ostentação e o luxo da nova burguesia se cristalizam no prédio que rompe a ocupação horizontal do recémocupado areal.

O livro enfatiza a importância da divulgação na aceitação da nova forma de morar, quando busca desvincular os apartamentos da sua condição de habitação coletiva, sempre associando-os a casas isoladas e independentes, pois, como explicar a aparição e difusão dos apartamentos se havia um horror generalizado pela habitação coletiva? A autora considera que o fato de os primeiros edifícios de apartamentos terem surgido em áreas nobres e modernas da cidade - como a 
Cinelândia, no Centro, e Copacabana, na Zona Sul e serem ocupados por estrangeiros e capitalistas, além de estarem associados a certas práticas próprias das classes média e alta, pode explicar, em parte, esta aceitação. Como afirma a autora "o edifício de apartamentos e Copacabana viriam a sintetizar um novo modo e morar que significava simplesmente ser moderno" (p.81).

Essa aceitação pode, também, estar vinculada às formas de divulgação através da promoção das suas virtudes pelos meios de comunicação - os jornais e as revistas -, que constroem a imagem da nova moradia coletiva através das características opostas aos dos antigos cortiços. "Rompe-se, dessa maneira, o elo de ligação com os tipos antecessores de habitaçóes coletivas" (p.87).

$\mathrm{Na}$ questão estética e formal, afirma-se que, na medida em que as habitações coletivas são apropriadas pela classe média, são incorporados elementos de diferentes estilos arquitetônicos, um processo de emburguesamento da habitação coletiva, além da transformação de seu conteúdo social no período abordado. A diferença entre as antigas habitações coletivas, destinadas às classes trabalhadoras, consideradas insalubres, $\mathrm{e}$ os novos prédios de apartamentos, destinados às classes média e alta, está em ser a primeira concebida por uma classe para a outra enquanto a segunda é a moradia da própria classe que formula conceitos de bem e mal morar. "Desde o início da polêmica ficou clara a articulação habitação coletiva/'desprovidos da sorte' e edifícios de apartamentos/burguesia" (p.133). Marca a diferença a utilização de habitação "multifamiliar" em substituição à habitação "coletiva".

Este simbolismo marca-se, principalmente, pela requalificação de elementos existentes, deixando patente que os edifícios de apartamentos não são nada do que as antigas habitações coletivas foram, e passam a ser tudo o que aquelas não haviam sido. Além do que, ao prestígio da moradia soma-se o prestígio do local da moradia, o "conceito da habitação coletiva foi renovado, transformando-se o seu sentido negativo em positivo e metamorfoseando o seu sentido simbólico" (p.141).

No que se refere ao espaço urbano, a abordagem se faz através das transformaçōes na morfologia e na estrutura urbana que acontecem com o início do processo de verticalização que, no caso do Rio de Janeiro, apresenta o predomínio da localização litorânea e do uso residencial, com mudanças quanto ao uso do solo e à distribuição da população.

No novo espaço urbano muda-se a relação entre habitação popular e habitação coletiva. Desde a proibição dos cortiços e a redução da tradicional forma de moradia popular, as favelas se multiplicam, localizadas próximo a possibilidade de trabalho, seja no setor da construção civil ou nas proximidades das moradias da classe média. É assim que a verticalização e a favelização dominam boa parte do cenário carioca, expondo a cidade sua face mais moderna.

Ao abordar a questão da modernidade, o livro aponta a habitação coletiva como expressão privilegiada da modernidade, e vai além do contexto habitacional da arquitetura e do urbanismo, buscando a interface entre as áreas temáticas da habitação e da modernidade. Nos itens específicos, a autora busca, em cada um, uma particularidade, uma constatação e uma observação sobre algum aspecto dessas transformaçōes. É na relação entre o individual e o coletivo, a moradia e o trabalho, a fragmentação do espaço e a exclusão social que busca estabelecer um paralelo entre a escala da cidade e a escala da habitação.

Concluindo, Lilian levanta discussões de grande pertinência ao mesmo tempo que proporciona uma leitura agradável, com exemplos e imagens que facilitam sua compreensão. O livro, que não pretende esgotar o tema, traz uma grande contribuição ao estudo da história das habitações no Brasil, principalmente considerando o percurso realizado - as transformaçōes arquitetônicas, urbanas, sociais e simbólicas da habitação coletiva no Rio de Janeiro do final do século XIX até os anos 30 do século XX. Sem dúvida, um percurso pouco explorado, com poucas publicações e muitas possibilidades dentro da historiografia da arquitetura brasileira.

Muito já se escreveu sobre as experiências de habitação coletiva no final do século XIX e princípio do século XX no Rio de Janeiro - como, por exemplo, Roberto Moura, em Tia Ciata e a Pequena África no Rio de Janeiro, e Lia de Aquino Carvalho, em Contribuição ao estudo das habitaçōes populares. Rio de Janeiro 1886-1906, além de outros, que mesmo não tratando especificamente do tema, abordam questōes referentes às formas da habitação das classes menos favorecidas como Visões da liberdade e Cidade febril, de Sidney Chalhoub, e Evolução urbana do Rio de Janeiro, 
de Maurício de Abreu, apenas para citar alguns. É importante destacar que o livro que Lílian nos apresenta se soma aos anteriores na história da habitação no Brasil, em particular, porque preenche uma lacuna ao estudar o edifício de apartamentos no período da transição para o modernismo, quando se verifica a mudança na forma de habitar, sua relação com o espaço urbano e a produção social de moradias. 